\title{
ENTRE REPRESENTACִÕES E DISCURSOS: OS SENTIDOS DA MATEMÁTICA ESCOLAR NAS FORMULAC̣̃̃ES DE DOCENTES
}

\begin{abstract}
RESUMO: Mediante o constructo teórico-metodológico, no entremeio da Teoria das Representações Sociais e da Análise do Discurso materialista, parte-se do incômodo de como e quais representações sociais são sustentadas, produzindo efeitos de sentidos sobre a matemática escolar, no discurso dos professores que a lecionam. O objetivo é analisar os efeitos de sentido sobre a disciplina. O campo teórico-analítico permite compreender o modo como a discursividade estrutura e processa tais representações. Dessa maneira, esta pesquisa revela as regularidades temáticas: a matemática escolar 1) está presente no cotidiano, 2) leva ao raciocínio lógico, 3) é imprescindível na formação de um cidadão. Ancoradas na organização do mundo contemporâneo, pela lei e pela regra, as significações docentes reiteram o efeito de transparência da disciplina como conhecimento imprescindível para todos.

Palavras-chave: Discurso. Representações sociais. Matemática escolar.
\end{abstract}

BETWEEN REPRESENTATIONS AND DISCOURSES: THE MEANINGS OF SCHOOL MATHEMATICS IN THE FORMULATION OF TEACHERS

ABSTRACT: Through the theoretical-methodological construct, with the Theory of Social Representations and the materialistic Discourse Analysis in between, we took as a starting point the nuisance of how and what social representations are sustained, producing meaning effects on school mathematics, in the discourse of teachers who teach it. The goal is to analyze the meanings effects about the discipline. The theoretical and analytical framework allows understanding how the discourse structures and processes these representations. As a result three thematic regularities were identified about school mathematics: 1) it is present in everyday life, 2) it leads to logical reasoning, 3) it is essential for being a citizen. Anchored in the organization of the contemporary world, by laws and rules, the meanings expressed by the teachers reiterate the transparency effect of the discipline as an indispensable knowledge for all.

Key-words: Discourse. Social representations. School mathematics.

\author{
Guilherme Adorno de Oliveira* \\ Luzia Marta Bellini** \\ Renata Marcelle Lara*** \\ ${ }^{*}$ Mestre em Educação para \\ a Ciência e a Matemática, \\ Universidade Estadual de Maringá \\ (UEM). Doutorando em Linguística, \\ Universidade Estadual \\ de Campinas (UNICAMP) \\ E-mail: guiadorno1@gmail.com \\ ** Doutora em Psicologia Social, \\ Universidade de São Paulo (USP). \\ Professora do Departamento de \\ Fundamentos da Educação da \\ Universidade Estadual \\ de Maringá (UEM). \\ E-mail: martabellini@uol.com.br. \\ * * Doutora em Linguística, \\ Universidade Estadual de Campinas \\ (UNICAMP). Professora do \\ Departamento de Fundamentos da \\ Educação da Universidade Estadual \\ de Maringá (UEM). \\ E-mail: renatamlara@yahoo.com.br.
}




\section{INTRODUÇÃO}

No decorrer do trabalho, apresentamos e sustentamos analiticamente a matemática escolar como produtora de sentidos e formadora de representações no imaginário social em um campo de conhecimento tido como estável e verdadeiro. As pesquisas em Educação Matemática têm mostrado novas im-possibilidades para a disciplina, apesar de, ao mesmo tempo, identificar a estabilização de significados pelos docentes. A compreensão dos movimentos de sentidos sobre o conhecimento matemático por professores que o ensinam constitui a temática da nossa investigação de mestrado, realizada entre os anos de 2009 e 2011.

Os incômodos iniciais surgiram da leitura da tese de Gomes (2003) que versa sobre o pensamento iluminista francês a respeito da matemática como parte da educação pública. No entanto, a pesquisa ganhou materialidade à medida que a composição teórico-metodológica entre a Teoria das Representações Sociais, de Serge Moscovici, e a Análise do Discurso materialista, fundada por Michel Pêcheux, funcionou no gesto analítico dos questionários e entrevistas realizados com professores de Matemática.

A matemática escolar elaborada pelos iluministas prescrevia, sobretudo, uma instrução geral dos cidadãos, devendo, então, formá-los, aprimorando seu raciocínio. Desse modo, a matemática escolar e o desenvolvimento do raciocínio para uma nova sociedade formaram uma equação que se perpetua ainda no presente (GOMES, 2003).

O estudo das representações sociais nos permite compreender as trocas simbólicas entre os professores de Matemática e sua relação com a institucionalização do conhecimento. No entanto, outros sentidos começam a funcionar para o gesto investigativo a partir dos questionamentos suscitados no trabalho com a Análise do Discurso. O entremeio teórico e metodológico da Teoria das Representações Sociais e da Análise do Discurso possibilitou reconstruir os elementos da investigação. Compreender a representação como estrutura e processo, em sua discursividade, constituída por determinações histórico-sociais, sustentou a base teórico-analítica da nossa pesquisa.

Mediante o objetivo geral de analisar o discurso de professores de Matemática sobre a matemática escolar, de modo a trabalhar as representações sociais, como estrutura e processo, em tal discursividade, e os efeitos de sentidos daí resultantes, nosso problema de pesquisa centrou-se em como e quais representações sociais são sustentadas, produzindo efeitos de sentidos sobre a matemática escolar, no discurso dos professores dessa disciplina.

Em percurso paralelo, a pesquisa foi ganhando outras materialidades à medida que os sujeitos pesquisados cederam escritos e vozes ao trabalho. O questionário, respondido por meio virtual-eletrônico, possibilitou formular critérios para que uma representatividade estivesse presente, abrangendo diferentes perfis de acordo com o conteúdo do exame estatístico. Quatro sujeitos participaram da entrevista, também explorada para a compreensão do discurso sobre a matemática 
escolar. Desse modo, construímos o corpus de análise pelo trajeto temático sobre as significações docentes da matemática escolar.

O questionamento discursivo nos possibilitou apontar três regularidades temáticas a respeito da matemática escolar: 1) está presente no cotidiano; 2) leva ao raciocínio lógico; 3) é imprescindível na formação de um cidadão. As determinações sociais e históricas apareceram materializadas no discurso dos professores pelo funcionamento da memória discursiva da forma-sujeito ${ }^{1}$ do capitalismo. Os dizeres produzem representações entre sua forma estrutural linguística e o processo histórico.

\section{DANDO LUZ À RAZÃO: A MATEMÁTICA ESCOLAR SOB A SOMBRA DO ILUMINISMO}

Para situar as condições de produção das significações docentes, existe um momento que nos possibilita entender a institucionalização da matemática como disciplina escolar: o Iluminismo. Gomes (2003) empreende um estudo da concepção de Educação Matemática de quatro pensadores iluministas: Denis Diderot (1713-1784), Jean Le Rond d'Alembert (1717-1783), Étienne Bonnot de Condillac (1714-1780) e Jean-Antoine-Nicolas Caritat, o Marquês de Condorcet (1743-1794). Na obra de cada um desses autores a pesquisadora estudou os seguintes aspectos: epistemológico (do conhecimento matemático); teleológicoaxiológico (finalidades e valores da Educação Matemática); didático-metodológico (meios utilizados para o ensino); e psicológico (concepção em relação ao acesso do conhecimento pelo sujeito). Os quatro filósofos traçaram um caminho para a matemática escolar em direção ao centro da instrução geral dos cidadãos, isto é, como base e instrumento principal que serve à formação da cidadania e ao desenvolvimento da racionalidade.

No campo da História, Harvey (2007) afirma que o projeto da modernidade desenvolvido no Iluminismo baseava-se em uma ordem de conhecimento propulsora da liberdade e engrandecimento do intelecto do ser humano. Os mitos, a vida mística e a religião não se localizavam mais em uma posição central no contexto iluminista. Consideradas como irracionalidades, as vivências baseadas no oculto, no não comprovado, no "lado sombrio da humanidade", deveriam ser abandonadas. Para que o projeto se consolidasse, o desenvolvimento precisava se apoiar na racionalidade.

Perry (1999) explica que as partes que compunham o desenvolvimento, isto é, ciência, moralidade e arte, estavam ligadas a valores independentes: verdade, justiça e beleza, respectivamente. Essa diferenciação era, segundo o autor, uma das vias do projeto iluminista. A segunda via estava enlaçada no uso dos campos libertos da religião no dia a dia para enriquecer as vivências. O movimento caminhou buscando uma ruptura com a Igreja. "Foi, sobretudo, um movimento secular que procurou desmistificar e dessacralizar o conhecimento e a organização social para libertar os seres humanos de seus grilhões." (HARVEY, 2007, p. 23). 
Os quatro filósofos defendiam a Matemática como essencial aos cidadãos, conforme Gomes (2003). Diderot se destacou pela defesa da Educação Matemática como um meio de reforma da sociedade. D'Alembert via na Matemática uma cadeia de verdade. Já Condillac entendia esse conhecimento como a base para a aprendizagem de todos os outros. Finalmente, Condorcet, que pertenceu a uma geração posterior e foi herdeiro da filosofia deixada pelos outros três, tinha a Matemática como exemplo da inteligência humana e essencial para a consolidação do projeto de uma nova França (GOMES, 2003). A emancipação intelectual, meta fundamental na França do século XVIII, em contraposição ao que estava estabelecido na ordem do conhecimento, tinha como princípio para seu desenvolvimento a Educação Matemática, a base para a razão.

As condições de produção do conhecimento disciplinar referentes ao período iluminista e seu processo de institucionalização são trabalhados à medida que os procedimentos analíticos são ancorados em relação ao material de pesquisa: os dizeres docentes.

\section{NO ENTREMEIO DE REPRESENTAC̣ÕES E DISCURSOS}

Como gesto pilar para a compreensão da memória que se perpetua pela institucionalização da matemática escolar, apresentamos os principais desdobramentos teórico-metodológicos da Teoria das Representações Sociais e da Análise do Discurso materialista. As teorias, norteadoras do movimento de entremeio, pulsam o gesto analítico da representação, em sua discursividade, como estrutura e processo, constituída por determinações sócio-históricas, no atravessamento do conteúdo pelo interdiscurso.

A Teoria das Representações Sociais (TRS) nasceu no campo da psicologia social, mas questionando-a com o objetivo de resgatar, concomitantemente, as dimensões psicológica e sociológica. Para Moscovici (2004), as duas dimensões se cruzam e também estabelecem novos limiares. O termo (composto) "representações sociais" não é mais entendido como um conceito estático, mas como movimento em processo.

A produção das representações sociais pode ser analisada sob a perspectiva de suas três determinações, apresentadas por Souza Filho (1995): a) existe uma "pressão à inferência" para que se explicite atitudes e posicionamentos frente a qualquer objeto, tema ou pessoa; b) há pontos de convergência delineados para serem parte de um grupo ou comunidade, identificando-se a eles por suas escolhas; c) a informação não está empregada do mesmo modo para todos os sujeitos, dispersando-se.

Para Moscovici (2004), os "modelos sobre" são socializados em determinados grupos de modo que sejam aceitos por todos. É parte essencial do próprio sujeito conseguir inferir significados para sua vivência, compartilhando algo que possa ser comum também aos outros. Não há um começo absoluto para esse processo. As representações estão sempre baseadas em outras representações. 
De acordo com Moscovici (2004, p. 35), "Nenhuma mente está livre dos efeitos de condicionamentos anteriores que lhe são impostos por suas representações, linguagem ou cultura". Convenção é o nome dado pelo autor para explicar tais efeitos. Uma consequência disso, para ele, é o fato de que "nós vemos o que as convenções subjacentes nos permitem ver e nós permanecemos inconscientes destas convenções".

O segundo funcionamento das representações sociais, o prescritivo, a "força irresistível", é descrito por Moscovici (2004, p. 36) como "uma combinação de uma estrutura que está presente antes mesmo que nós comecemos a pensar e de uma tradição que decreta o que deve ser pensado". As representações sociais não são criadas pelos sujeitos, mas "re-pensadas, re-citadas e re-apresentadas", com início antes mesmo do pensado. Existe uma memória que se perpetua pela linguagem e produz um elo com o conjunto de sentidos prévios, impedindo fugir de classificações anteriores; um processo de naturalização em que "quanto menos pensamos nelas, quanto menos conscientes somos delas, maior se torna sua influência”, de acordo com Moscovici (2004, p. 42).

Um ponto para entender a dinâmica das representações sociais se refere à familiarização, segundo Jodelet (2005). Tudo aquilo que o sujeito conhece, o familiar, seja por herança cultural ou por experiência individual, ampara o agir em mundos desconhecidos, o não familiar. Quando se depara com o não familiar, o sujeito precisa explicitar o que faz parte do consenso, mas somente o que é alcançável por ele. Familiarizar é um processo independente de vontades. Jovchelovitch (2000, p. 41) compreende que a "construção de representações sociais" tem nas "estruturas históricas e sociais alguns de seus elementos principais”. As representações sociais ainda se ligam "a processos simbólicos e ideológicos, com a dinâmica e com a energética social." (JODELET, 2005, p. 46).

Jovchelovitch (2000) explica que as representações sociais estão envoltas da simbologia que extravasa o imaginário, a identidade e a manifestação cultural. Logo, as representações não podem ser consideradas no sentido estrito do termo. Representam, mas não refletem o real. Para Jodelet (2001), as representações sociais dirigem as condutas humanas (posicionamentos, interpretações, tomadas de decisões) porque são as responsáveis por familiarizar o desconhecido, geralmente, nomeando ou estabelecendo a relação simbólica com aspectos do cotidiano. As representações sociais são cristalizadas na linguagem e nas formas sociais. Moscovici (2004) entende que a sua teoria não toca em certos pontos e nem define modos de investigação porque se mantém uma teoria aberta. A partir de tal abertura, nossa pesquisa toma a Análise do Discurso (AD) para trabalhar os pontos não tocados pela TRS de Moscovici.

Elencar a AD não significa uma apropriação unicamente de sua metodologia. Teoria pressupõe metodologia, como mostra Orlandi (2009). Para que possamos explorar o percurso teórico-metodológico, explicitamos parte dos princípios e procedimentos da AD que são fundamentais para a construção do nosso trajeto teórico-analítico. 
Como explica Orlandi (2009, p. 15), a AD não tem como objeto de estudo a língua, porque é o discurso o motivo de sua prática; "procura-se compreender a língua fazendo sentido, enquanto trabalho simbólico, parte do trabalho geral, constitutivo do homem e da sua história". Para Orlandi (1988, p. 19), a AD caminha por três territórios do conhecimento científico: o materialismo histórico, a linguística e a teoria do discurso. Falamos em caminhar por esses territórios em razão de a AD ser, como aponta Orlandi (2009), uma disciplina de entremeio, ou seja, apresenta questionamentos em cada teoria que toma em seu auxílio para entender o funcionamento do discurso.

A noção de discurso evoca as bases sobre a qual a AD se firma. Para Orlandi (2009), o discurso não pode ser confundido com "mensagem" ou "fala". Deve-se considerar que a $\mathrm{AD}$ não entende língua e sujeito como transparentes. $\mathrm{O}$ sujeito, afetado pela ideologia e pelo inconsciente, não apreende sentidos como eles se pudessem ser "pegos", mas os interpreta a partir das condições sócio-historicamente determinadas. Por esse motivo, Orlandi (2009, p. 21) afirma, recuperando a definição de Michel Pêcheux, que "o discurso é efeito de sentidos entre locutores". Ao lidar com a noção de efeito, a AD trabalha na impossibilidade do controle total dos sentidos.

Sendo assim, o estudo do discurso, preocupado com a formação dos sentidos, tende a transcender a análise puramente linguística, buscando compreender aquilo que lhe é exterior. Conforme Orlandi (1996, p. 55), nada é de desinteresse para o sentido entre o determinismo social e linguístico inscritos na linguagem: "Não são apenas as palavras e as construções, o estilo, o tom que significam. Há aí um espaço social que significa". $\mathrm{Na} \mathrm{AD}$, as condições de produção do discurso produzem sentido, determinando-o. Orlandi (1996, p. 27) afirma que "a relação entre as condições sócio-históricas e as significações de um texto é constitutiva e não secundária”.

Desse modo, o processo de análise da $\mathrm{AD}$ procura levar em conta os outros discursos não ditos, esquecidos e rejeitados, para compreender os efeitos de sentido entre locutores. O método analítico, afirma Orlandi (2009), procura compreender o funcionamento dos sentidos. A AD é uma disciplina de interpretação, mas busca problematizar o valor do discurso, explicitando como certos sentidos são possíveis. Compreender é "conhecer os mecanismos pelos quais se põe em jogo um determinado processo de significação" (ORLANDI, 1988, p. 117).

$\mathrm{Na}$ análise que propomos, buscamos trabalhar a historicidade do discurso sobre a matemática escolar, relacionando o dito ao não dito. Se, como afirma Orlandi (2005, p. 93), "a incompletude é o índice da abertura do simbólico, do movimento do sentido e do sujeito, da falha, do possível", o discurso dos professores significa além de seu dizer sobre a Matemática na escola. Significa, também, um dizer sobre o social. Movimento no jogo ideológico, as concepções dos professores partem de um imaginário social: "Em todo dizer há confronto do simbólico com o político: todo dizer tem uma direção significativa determinada pela articulação material dos signos com as relações de poder" (ORLANDI, 2005, p. 129). 
$\mathrm{Na}$ apresentação do trabalho de Moscovici, encontramos a afirmação de Duvenn (2004, p. 20) mediante a qual iniciamos os deslocamentos para significar nossa pesquisa: "o próprio conceito de representação possui um sentido mais dinâmico, referindo-se tanto ao processo pelo qual as representações são elaboradas, como às estruturas de conhecimento que são estabelecidas". O autor reconhece que o conceito de representação social produz sentidos diversos nos trabalhos da área pela dinamicidade com a qual é encarada, sem se reduzir a esta ou aquela definição. Entretanto, existem duas características notáveis: as estruturas (de conhecimento) e o processo (pelo qual a representação é formada).

Em nossa pesquisa, trabalhamos justamente as características de estrutura e processo apontadas por Duveen (2004) pela relação com o discurso. Nossa proposta é compreender a representação social, como processo e estrutura, em sua discursividade, determinada por outros discursos, como a memória discursiva ${ }^{2}$, em funcionamento da sua apresentação como conteúdo. Não se trata de realizar uma fusão epistemológica, mas de trabalhar analiticamente a não oposição entre representação e discurso, ou seja, de não trabalhar a complementaridade, mas o entremeio.

\section{SIGNIFICAÇÕES DOCENTES SOBRE A MATEMÁTICA ESCOLAR}

O trabalho teórico é a possibilidade-suporte da construção dos instrumentos da pesquisa, delineando os passos da metodologia. O diálogo constante entre teoria e metodologia, efeito do trabalho também em AD, propicia a criação de espaços para que os discursos ganhem materialidades e o gesto analítico torne-se prática de linguagem.

O questionário foi um dos recursos pelo qual optamos com o intuito de fazer um recenseamento inicial dos professores de Matemática da Rede Estadual de Ensino de Maringá, no Paraná. O instrumento, respondido por 97 docentes, é composto por dez questões, sendo uma delas destinada à identificação, sete questões fechadas que versam sobre idade, formação acadêmica e trabalho docente, e duas abertas sobre o porquê da presença da disciplina na escola e como se dá sua aprendizagem.

No segundo momento de instrumentação, nossa entrevista foi formulada com o foco exclusivo na matemática escolar. Trouxemos assuntos que rodeiam a temática para tentar explorar as respostas dos professores ${ }^{3}$ de modo a suscitar informações e experiências outras, diferentes das citadas no questionário, relacionadas à matemática escolar. O intuito foi "rastrear momentos privilegiados da equivocidade da língua, que são manifestados na forma de lapsos, silêncios, interrupções, rupturas do pensamento, bem como nos acréscimos e, até mesmo, no riso", conforme afirma Andrade (2008).

O modo de entrevista escolhido foi a semiestruturada porque possibilita a construção de perguntas sem impedir a intervenção quando acreditamos ser conveniente entender ou aprofundar determinadas questões. O roteiro inclui 20 
perguntas divididas em três momentos. Os dois primeiros retomam perguntas do questionário (dados gerais dos professores e duas perguntas abertas: Para você, por que a Matemática é uma disciplina escolar? e O que significa aprender Matemática no seu ponto de vista?). O terceiro momento da entrevista foi construído com o propósito de "dar voz" aos entrevistados, ou seja, deixá-los falar sobre a matemática escolar explorando as margens do assunto. Para atingir tal propósito, formulamos as perguntas parafraseando as duas produzidas para o questionário. Como expõe Andrade (2008), é parte das condições de produção da entrevista que, ao se expressarem oralmente, os entrevistados façam recorrências e associações mais diretas, sem o planejamento que a escrita fornece. Além do contraponto, as duas perguntas concernem aos pontos tangenciais das representações sociais da matemática escolar. Justificando a presença da Matemática na escola e explicando como se dá o aprender da Matemática, os professores recorrem ao conhecimento e às experiências em sala de aula, aspectos que constroem as representações sociais. Além do roteiro de perguntas, já estavam previstos certos questionamentos, principalmente os "comos" e "porquês", para instigar os entrevistados a discorrer mais sobre o que falavam, tentando evitar o campo do estabilizado, das afirmações já prontas.

Comunicamo-nos com quatro professores, por e-mail ou telefone, solicitando a colaboração na segunda parte da pesquisa. Com a resposta positiva, o passo seguinte foi explicar qual seria o tema das perguntas e também marcar o dia, horário e local, de acordo com a preferência do professor contatado; comparecemos, segundo as informações acordadas previamente, e novamente foi exposto qual era o objetivo da entrevista. Esses quatro professores foram selecionados dentre os demais seguindo o critério de representatividade quanto às informações prévias interpretadas a partir dos questionários, isto é, tentando abranger as características diferenciadas no que dizia respeito à formação acadêmica, idade e tempo de docência.

A disposição do material composto pelas formulações linguísticas sobre a matemática escolar, mediante situações de pergunta e resposta, no gesto de leitura discursiva, funciona, em sua opacidade, para além do emaranhado de textualidades isoladas. No entendimento de Guilhaumou e Maldidier (1997), a materialidade linguística do discurso é também histórica e, portanto, as palavras por si não permitem que o arquivo, como recorte, seja dado antes de um movimento interpretativo. $\mathrm{O}$ trajeto temático, descrito por Guilhaumou e Maldidier (1997, p. 168) como "processo essencialmente de compreensão", permitiu construir o arquivo de análise.

O trajeto temático formulado como as significações da matemática como/pelo professor de Matemática conjugado à pergunta discursiva "Do lugar enunciativo de professor de Matemática (lugar legitimado/reconhecido como tal na sociedade), que significações são (possíveis de ser) enunciadas sobre a matemática escolar, na sustentação de uma representação social dela, considerando a forma como esses sujeitos estão ou não afetados institucionalmente?", nos permite compreender o funcionamento do discurso de docentes. A análise indicou três regularidades temáticas, isto é, reproduções contínuas de conteúdo sustentando um tema. Tais regularidades foram formuladas da seguinte maneira: a matemática 
escolar (1) está presente no cotidiano, (2) implica no raciocínio lógico, (3) leva à formação do cidadão. Assim podemos perceber que esses sentidos são constitutivos da forma-sujeito do capitalismo.

No estudo das representações que propomos, a Análise do Discurso proposta por Pêcheux configura-se como um olhar para além do linguístico. Sem delineamento prévio, a teoria de Moscovici (2004) se abre para uma abordagem discursiva das representações, como conceito e fenômeno, processo (memória) e estrutura. No entanto, em suas características de conteúdo, as regularidades temáticas citadas anteriormente não constituem a totalidade das representações, como trabalhado por Moscovici (2004) e Jodelet (2001). Há o processo (a memória) do conhecimento formulado pelos sujeitos. A análise tensionou, desse modo, as determinações históricas e sociais que constituem as formulações da representação (como conteúdo) chamada, neste trabalho, de regularidade temática; uma tensão possível de ser analisada pelo contraponto dos dizeres sobre a Matemática em outras instâncias.

Partimos da proposta do pesquisador brasileiro Ubiratan D’Ambrósio (1999, p. 105-6), fundador da teoria Etnomatemática ${ }^{4}$, em sua conceituação de conhecimento como "o conjunto dinâmico de saberes e fazeres acumulado ao longo da história de cada indivíduo e socializado no seu grupo", que, depois de distorcido na sua apropriação pelas "estruturas de poder", é disciplinarizado, fracionado em partes, em "áreas de competência para justificar ações setoriais no exercício do poder". Como uma forma de conhecimento, o que chamamos Matemática é um conhecimento partido, com limites bem definidos para seu ensino e desenvolvimento na sociedade ocidental. O que existe, para D’Ambrósio (2002), são matemáticas. Ele pensa essa forma de conhecimento sem uma definição clara e precisa como se fosse um sistema fechado. $\mathrm{Na}$ divisão silábica da palavra, o autor sugere, mas não define, uma conceituação: arte ou técnica (tica) de explicar e conhecer (matema). Para seu programa de estudo, D’Ambrósio (2002) introduz o termo Etnomatemática, pois o interesse é entender essas artes ou técnicas de explicar e conhecer em realidades sociais, históricas e culturais (etno) localizadas, mas nem por isso estanques. Apesar de falar em artes e técnicas, o autor não exclui maneiras distintas de apresentação das matemáticas. O estudioso argentino Luis Antonio Santaló entende o conhecimento matemático também nas suas características de filosofia, ciência e magia.

Ao mencionar algumas características da matemática (escolar) em diferentes níveis de ensino, desde os primeiros anos de escola até os estudos no Ensino Superior, Santaló (1994, p. 12) afirma que "esta diversidad de conceptos acerca de lo que se entiende por matemática dificulta, y tal vez imposibilita, definirla con precisión". Esse é o motivo que o leva a explorar o conhecimento matemático sob distintos aspectos, intercambiáveis uns aos outros. Santaló (1994, p. 17) comenta que "la parte más visible de la matemática la constituyen sus aplicaciones prácticas y su necesidad para la técnica”. A Matemática é reconhecida ou valorizada pela técnica, apesar de não ser a única forma e apresentá-la: "Ni la matemática pura, ni 
la matemática práctica, con todas sus computadoras y sus grandes posibilidades de cálculo, podrán resolver los grandes problemas”, de acordo com Santaló (1999, p. 22). A ideia de imobilidade e exatidão da Matemática tem sido desconstruída, segundo o autor, pelos novos modos de estudá-la desde o século XX, preocupando-se com fenômenos incertos e não controlados no espaço anterior de pesquisa, que é bem delimitado.

Para um grupo de pensadores da Sociologia da Matemática, "só pelo reconhecimento cultural da matemática se poderá compreender melhor sua natureza”, como explica Wilder (1998, p. 6), ou seja, a matemática, como parte da cultura e produto dela, é uma "invenção humana", na medida em que é pensada por alguém. O autor expõe alguns exemplos de como a Matemática ${ }^{5}$ se desenvolveu em diferentes culturas, como a grega e a chinesa, dando evidências de que essa área faz parte de um processo cultural mais amplo do que a simples restrição à sua lógica interna. Wilder (1998, p. 16) declara que "tal como podem existir, e existiram, diferentes culturas, diferentes formas de pensamento e conseqüentemente diferentes matemáticas [...] há apenas o relativo". É a sustentação do conhecimento pelo social. Bloor (1998a, p. 51) entende que "se a matemática é sobre os números e as suas relações e se estes são criações sociais e convenções, então, de facto, a matemática é 'sobre' algo social'. Mediante o seu social e o relativo a ele (BLOOR, 1998a), um sistema não fechado e único (D’AMBRÓSIO, 2002), as diferentes características e apresentações (SANTALÓ), pergunta-se o porquê da não propagação de uma matemática diferente ou alternativa. Bloor (1998b, p. 53-4) responde que "uma matemática alternativa pareceria errada e inadequada [...] em vez de existir coerência e concordância, poderia ser exactamente a falta desse consenso o factor que distinguiria a matemática alternativa da nossa". Nos recortes analisados, buscamos compreender as bases de sustentação para "nossa matemática” produzir certos sentidos e não outros.

\section{RECORTE - RESPOSTA DE P1 À PERGUNTA “POR QUE A MATEMÁTICA É UMA DISCIPLINA ESCOLAR"}

Porque a Matemática é a mesma, mesma explicação que às vezes eu respondo para os alunos que perguntam por que que precisa aprender Matemática. A gente tem a Matemática o tempo todo na vida. Seria impossivel você viver sem ela. A partir do horário, da hora que você abre os olhos, você olha no relógio você está usando Matemática. Você planeja tempo que você vai gastar, que horas você tem que acordar, a distância que você tem que andar até o trabalbo. Tudo isso é Matemática. Sem contar, é, todas as outras coisas que vão acontecendo diariamente. Então, a Matemática é fundamental nisso. Então, porque a matemática na escola também ela é essencial. Porque quando você aprofunda um conteúdo matemático, você consegue faz̧er ligacões, isto ainda na Educação Básica, você consegue fazer ligacões e o próprio raciocínio matemático, a lógica que aquele, aquele quando você desenvolve o raciocinio lógico, quando você desenvolve a lógica no teu dia a dia, e você tem a lógica presente no teu dia a dia, você, até problemas do teu dia a dia, não necessariamente ligados à Matemática, você vai usar, você vai usar a lógica e você resolve problemas mais facilmente do dia a dia. Então, ela é essencial. É. Primeiro, porque você não vive sem ela no seu dia a dia e você consegue fažer interligações dos conteúdos matemáticos. Então, ela é essencial por conta disso. 
A resposta dada pelo professor P1 funciona constitutiva e imaginariamente para o sujeito como o que é possível (e deve) ser dito para um pesquisador. Em um primeiro gesto de leitura das palavras de P1, afere-se que as explicações retomam os conhecimentos mobilizados em seu dia a dia como docente da disciplina, lugar social legitimado, reconhecido como possível de criar formulações sobre a matemática escolar. Há um duplo jogo de lugares: o professor de sala de aula e o entrevistado de uma pesquisa acadêmica. A fala mesma explicação que às vezes eu respondo para os alunos remete, como conteúdo, à autoafirmação do lugar de professor. É a fala de alguém que responde e explica aos alunos, ao entrevistador. Em AD, no entanto, o gesto analítico pede que o trabalho com a descrição e a interpretação, como exposto por Pêcheux (1997), seja realizado em batimentos dos dois movimentos da análise. É na materialidade, linguística e histórica, que é possível compreender o discurso, a ideologia (ORLANDI, 2009).

Problematizamos os trechos recortados no intuito de tensionar os sentidos produzidos sobre a matemática escolar. Em um momento do trecho, P1 tem a seguinte fala: A gente tem a Matemática o tempo todo na vida. Seria impossível você viver sem ela. É o primeiro tópico apresentado à pergunta Por que a Matemática é uma disciplina escolar depois de P1 ponderar que a resposta é a mesma dada aos seus alunos sobre o porquê da aprendizagem da Matemática. Nas quatro entrevistas, e mesmo nas conversas informais com os professores durante a aplicação dos questionários, os docentes reiteraram que explicações sobre a presença da Matemática na sala de aula é algo pedido com frequência pelos discentes. P1 retoma essa memória, ainda que não se dê conta, ao introduzir a "mesma explicação" dada aos alunos.

$\mathrm{Na}$ consideração literal das palavras, agora especificamente nos questionários, vemos expressões repetidas e sintaticamente estruturadas de forma semelhante: está presente em todos os momentos de nossa vida (Regularidade Discursiva - RD1); ela faz.parte de tudo que fazemos durante o dia, e em todos os momentos está presente (RD2); está presente na nossa vida em todos os momentos (RD3); A matemática está intimamente ligada a tudo o que fazemos (RD4); a matemática está presente em tudo o que nos cerca (RD5); farparte de tudo e esta em todas as necessidade (RD6). Na totalidade material de análise, a repetição de conteúdo dessas afirmações se mantém na maioria das respostas ${ }^{6}$. O interesse, nesta repercussão, está em como podemos analisar no tocante a uma regularidade discursiva, ou seja, como produção de sentidos de uma materialidade linguística, na História. Tomando a definição de memória discursiva em Orlandi (2009, p. 31) e considerando que o interdiscurso "disponibiliza dizeres que afetam o modo como o sujeito significa em uma situação discursiva dada”, os conhecimentos mobilizados pelos entrevistados estão afetados por uma historicidade que os constitui, produzindo certos sentidos e não outros. Quantitativamente, chegamos a um fato significativo. Os professores falam da Matemática presente na vida e no cotidiano. É uma das justificativas para ela ser uma disciplina escolar. Além do que é enunciado, para entender como se dá o efeito de sentidos para os sujeitos, o questionamento do lugar social e da posição do discurso permite explicitar os processos de identificação, as filiações discursivas do professor de Matemática que 
pesquisamos. De acordo com Orlandi (2009, p. 60), podemos “descrever a relação do sujeito com a sua memória”.

O professor em sala de aula ocupa um lugar ${ }^{7}$ legitimado na sociedade como aquele que sabe, o sujeito que ensina. Portanto, as relações estabelecidas entre os saberes ensinados são produzidas com o fim de obter uma unidade que possa ser apre(e)ndida, logicamente organizada entre causas e consequências. Pêcheux (1997) ressalta que a busca pelo mundo normal(izado), estabilizado, é própria da constituição do sujeito (e dos sentidos). No discurso pedagógico (DP) há o funcionamento de certa cientificidade, o que caracteriza como a verdade para ser dita. Todavia, a validade do conhecimento não é suficiente. É preciso justificar essa validade. Orlandi (1996, p. 18, grifo nosso) afirma que o DP “cria uma visão de utilidade, fazendo com que o DP apresente as razões do sistema como razões de fato". A resposta dada por P1 como sendo a mesma dada a seus alunos pode remeter a essas razões do sistema. Em um primeiro momento, podemos falar que a razão da Matemática ser uma disciplina, de acordo com P1, é de atender às exigências institucionais do sistema escolar. A Matemática é apontada, ali, como algo manifestado na vida de todos e que nos é impossível não tê-la, não usá-la. Notemos que a Matemática aparece como algo a ser possuído, um substantivo próprio, concreto e singular (a Matemática; ela = Matemática). Adquire-se um valor evidente de existência e é esquecido que o referente, a Matemática, é uma construção histórico-social, ou ainda, seguindo os estudos de D’Ambrósio (2002), é uma apropriação de diferentes saberes que resultam no que conhecemos hoje, na sociedade ocidental escolarizada, como Matemática. O autor sublinha o caráter hegemônico da forma como o conhecimento nos é apresentado, com as diferentes possibilidades e os conflitos apagados na sua exposição disciplinar. O que é ensinado nas escolas hoje, para D’Ambrósio (2002), é um recorte com limites bem marcados e que, por isso mesmo, perde as dimensões diversas que as matemáticas podem oferecer para o estudante. Ainda que essas características da constituição social não estejam enunciadas no trecho dito por P1, não negamos que ele as conheça. Mas, entre os dizeres possíveis, o que está formulado no discurso não retoma a historicidade própria do conhecimento. A Matemática existe, temos o tempo todo na vida e não vivemos sem ela. Esse pré-construído, funcionando como o sempre já aí do discurso, sobre a Matemática, acaba por determinar, ou restringir, o desenvolvimento posterior da fala do entrevistado.

D’Ambrósio (2002) e Veschi (1996) permitem-nos pensar as diferenças para duas instâncias, Matemática e tempo, e, também, uma regularidade que as enlaçam: o controle sobre a vida. As situações citadas vêm depois da fala de que a Matemática existe o tempo todo na vida. No funcionamento discursivo, como preenche todos os espaços desta vida e na impossibilidade de viver sem ela, a Matemática produz um valor tão interligado ao sujeito que pode ser entendida como a própria vida. Esta, por sua vez, é a vida cronometrada no e pelo tempo. Os horários de levantar, de sair de casa e de chegar ao trabalho, com um planejamento de quanto tempo pode ser gasto para cada atividade. As materialidades linguísticas dessas 
condições de produção circulam socialmente nas frases: Tempo é dinheiro e Não se pode perder tempo, entre outras formulações. A Matemática é, em P1, a forma de regularizar esse tempo, gastá-lo, adequá-lo ao tempo do trabalho, do capitalismo e, assim, regularizar, gastar e adequar também o sujeito.

Em relação às quatro entrevistas (P1, P2, P3 e P4), em algum momento os docentes citaram exemplos dessa Matemática do dia a dia, do cotidiano. Foram comentados assuntos relacionados ao trabalho ou ao uso do dinheiro. Nos questionários, as situações desse tipo seguiram os mesmos parâmetros de conteúdo das entrevistas, como no recorte anterior. Sem a matemática ficaria impossivel sair do ensino regular preparado para o mercado de trabalho, muito menos para concorrer a algum concurso público ou até um vestibular (RD7) e A matemática está inserida no mundo dos negócios, no comércio, na saúde, na geografia, na escola, em casa e em nosso dia a dia (RD8).

Pesquisador brasileiro em Educação Matemática, Machado (1993) relata, em estudo sobre os lugares comuns dos educadores, tentativas dos professores em estabelecer analogias com a realidade, os contextos do cotidiano. Essa aparência, a falsa necessidade de fazer aplicações práticas, é agravada, conforme o autor, pelo uso da Matemática em outras ciências e nos meios de comunicação, na forma de números e dados gráficos. O que funciona como realidade no recorte dos questionários é o que pertence ao campo do trabalho e da sociedade organizada em instituições de mercado. Em RD7, a disciplina Matemática, no sentido estrito, e a escola, em sentido amplo, possuem uma função definida: preparar o aluno para o mercado de trabalho. É incontestável que seja assim. O sujeito estuda para exercer sua cidadania, ser consciente de direitos e deveres e se preparar para o trabalho. Faz parte da vida de qualquer cidadão (RD8). O sujeito jurídico e o cidadão fazem parte de um escopo de estudos na AD ao tratar da forma-sujeito do capitalismo.

Orlandi (1996) afirma que o indivíduo da Idade Média estava interpelado em sujeito por uma ideologia diferente do contemporâneo. Enquanto o sujeito medieval tem na Igreja a base para a construção simbólica do mundo, determinado por uma ordem religiosa, o sujeito capitalista vive no interior de uma tensão provocada pela luta de poderes de consumo. O essencial e o fundamental da Matemática, enunciados na entrevista, relacionam-se, assim, a viver na constante disputa pelos lugares de ser sujeito, de consumir. Os exemplos de P1 da Matemática manifestada no cotidiano remetem a esses lugares. Ao dizer que você planeja tempo que você vai gastar, que horas você tem que acordar, a distância que você tem que andar até 0 trabalho, o docente, interpelado em sujeito de seu discurso, põe em funcionamento as regras do sistema capitalista, não apenas por citar a rotina do sujeito que trabalha, mas ainda por explicitar as necessidades impostas a ele. Tempo que você vai gastar, você tem que acordar, você tem que andar são formulações que remetem ao campo das exigências. O sujeito tem que fazer algo sempre, é necessário, é imprescindível, é essencial. O sentido de Matemática, portanto, não se distancia da formação ideológica desse sujeito, isto é, da ideologia do capitalismo materializada em discurso pela linguagem expressa na fala dos entrevistados. A forma-sujeito capitalista é um espaço ocupado pelo professor ao apresentar as razões do sistema, ou seja, o 
tempo na vida cotidiana, como razões de fato, supostamente evidentes, sobre a Matemática ser uma disciplina, algo a ser aprendido.

$\mathrm{Na}$ segunda regularidade temática, a matemática escolar implica no raciocínio lógico, identificada em formulações do tipo uma matéria que faz você raciocinar, que faz vocêpensar, uma matéria que ajuda ele (P2), buscamos compreender, no trabalho com a memória discursiva, as significações inscritas em uma historicidade não visível pelo conteúdo. Existe nessa regularidade um pensamento idealista, como referido por Mariani (2010), que responde a uma exigência de mercado e, ao mesmo tempo, impossibilita a racionalidade pela técnica.

A forma como a terceira regularidade temática é apresentada, a matemática escolar leva a formação do cidadão, não se desvincula das outras regularidades. No dizer é uma disciplina que leva ao desenvolvimento da pessoa mesmo, formação do cidadão, que leva a pessoa a pensar, a tomar decisões (P3) a cidadania, sempre um vir a ser para o sujeito, no Brasil, como expõe Orlandi (2002), se dá não diretamente pela aprendizagem da matemática, mas porque funciona o efeito de aplicar no dia a dia o raciocínio lógico, e, por isso, pensador (supostamente) consciente de seus direitos e deveres.

\section{CONSIDERACְ̃̃ES FINAIS}

Explicitar as determinações que constituem a emersão das três regularidades temáticas analisadas é trabalhar com os discursos que sustentam as representações sociais como modelo linguístico dos professores. A memória discursiva, da forma como apresentamos, é a possibilidade de trabalhar com o pertencente à formação da representação, como processo constituinte, sobre o qual Moscovici (2004) expõe, ou seja, como um processo que é dividido em objetivação e ancoragem. O primeiro diz respeito, na explicação de Jodelet (2001), ao efeito ligado à constituição do sujeito, na forma como os elementos são organizados. Já a ancoragem

“enraíza a representação e seu objeto numa rede de significações que permite situá-los em relação aos valores sociais e dar-lhes coerência [...] essencialmente no que se refere à realização de sua inscrição num sistema de acolhimento nocional, um já pensado”, nas palavras de Jodelet (2001, p. 38).

O trabalho da memória, segundo a autora, age no pensamento atual configurando-o pelo já pensado, antes mesmo de o sujeito poder pensar. Há no processo uma "naturalização das noções", isto é, "lhes dá valor de realidades concretas, diretamente legíveis e utilizáveis na ação sobre o mundo e os outros”, que instrumentaliza o saber, configurando-o numa função de interpretar o mundo, conforme Jodelet (2001, p. 39).

Orlandi (2002) afirma que o sujeito contemporâneo, ocidental-capitalista, possui duas formas essenciais de organização do seu viver no mundo: a lei e a regra. 
A autora entende a materialização dessas duas instâncias nas formulações do tipo "Se...então". Assim, o discurso jurídico, dos direitos e deveres, e o discurso sobre a Matemática, presidem "a forma de nossa sociedade, em seus condicionantes, com suas relações de produção, de divisão do trabalho, do lucro, das relações econômicas e sociais gerais. O jurídico e a Matemática são os dois pilares da forma racionalizada (abstrata) de nossa cultura", de acordo com Orlandi (2002, p. 237-8). Cotidianidade e raciocínio lógico são conhecimentos necessários para a construção de um lugar social legitimado para o sujeito: o cidadão. A aprendizagem matemática é condicionante para ser cidadão. $\mathrm{O}$ ensino dessa disciplina forma o cidadão.

Nesse contexto, as representações sociais sobre a matemática escolar, analisadas no discurso dos professores, como estrutura e processo, são compostas tanto pelas regularidades temáticas como pelas determinações que as constituem. Apreendemos, assim, as representações, conforme afirma Jodelet (2001, p. 39), em complexidades diversas (conteúdo e discurso), "desde a palavra até a teoria, que serve de versão do real; desde os conceitos ou categorias até as operações de pensamento, que os relacionam". Na perspectiva discursiva, corroboramos com Orlandi (2002, p. 238) quanto à Matemática servir "muito para se apreciar o funcionamento dos sujeitos", ou seja, "pode nos fazer entender processos cognitivos, mas também, diríamos, sobretudo, discursivos, históricos, sociais, importantes/ relevantes para o seu modo de significar, de se significar, na compreensão de novas formas culturais e sociais".

O gesto analítico buscou, portanto, compreender o discurso para além de sua aparente evidência. O conhecimento matemático, pela fala dos professores, remete ao próprio sujeito contemporâneo, assujeitado aos direitos e deveres do funcionamento discursivo do jurídico, perpetuado ele mesmo pela escrita simbólica das leis e regras do mundo semanticamente normal (ORLANDI, 2002; PÊCHEUX, 1997).

O campo de estudos fundado com a criação dos primeiros programas de pós-graduação stricto sensu nas áreas envolvidas em educação para a ciência e a matemática já se realizou como um modo de questionar certos efeitos de evidência no interior das pesquisas em educação (no geral), mostrando as especificidades do ensino de cada disciplina. No entanto, também criou barreiras ao estabilizar outras evidências. O gesto proposto nesta pesquisa tensionou o que se apresenta como verdade no campo da Educação Matemática. Compreender a exterioridade constitutiva e negar a naturalização é exercer o político da linguagem, abrindo-se para o impensado, (ainda) irrealizado também na matemática escolar.

Se o político da linguagem é sua relação polissêmica com o simbólico, explicitar a movência da memória nos dizeres de um conhecimento é a prática política de desnaturalizar o que é certo, estável, semanticamente normal. As metodologias de ensino apresentam-se nos cursos de formação de professores como alternativas de proceder com a matemática em sala de aula. Problematizando, investigando, modelizando, informatizando, geometrizando sem andar. Se os sentidos de matemática permanecem enraizados apenas pelo interior de uma disciplina, 
os modos de conduzir a aula reproduzirão os mesmos sentidos, ou seja, é a técnica pela técnica. A representação da matemática escolar não muda, apenas se adapta ao não familiar e torna as metodologias familiares. Não há movimento de sentidos, mas repetição materializada em outras formas.

Os efeitos produzidos por esta investigação nos levaram a compreender o funcionamento dos sentidos da matemática escolar nas vozes de docentes para além de seu conteúdo visível. A análise percorreu os caminhos da materialidade, escutando gritos, sussurros e silêncios, audição do simbólico que é sempre incompleta. Há regularidades nos dizeres sobre a matemática escolar e elas estão ancoradas no funcionamento de uma memória discursiva organizada pela lei e pela regra. No entanto, o gesto não se esgota. O (des)encontro entre representação e discurso traz considerações, mas também é o momento de novas perguntas. Questionar pelas representações sustentando sentidos se dá pela constituição teórica amparada na prática de análise. A tentativa de deslocamento da empiria é a abertura para o desconhecido do ensino das matemáticas. Desestabilizar o normal dentro das pesquisas em Educação Matemática reclama que outros sentidos sejam escutados.

\section{NOTAS}

${ }^{1}$ Conceito da Análise do Discurso materialista, a forma-sujeito adquire sua significação teórico-metodológica no trabalho do sujeito como um falante que "não opera com a literalidade [...] uma vez que não há sentido único e prévio, mas com um sentido instituído historicamente na relação do sujeito com a língua e que faz parte das condições de produção do discurso.” (ORLANDI, 2009, p. 52).

${ }^{2} \mathrm{~A} A \mathrm{AD}$ trabalha a memória em relação ao discurso e não como puramente cognitiva ou neurofisiológica. Baseada em Michel Pêcheux, Orlandi (2009, p. 31) define a memória discursiva como "o saber discursivo que torna possível todo dizer e que retorna sob a forma do pré-construído, o já-dito que está na base do dizível, sustentando cada tomada de palavra".

${ }^{3}$ Uma análise primária dos questionários, antes da formulação da entrevistas, já apontava para uma regularidade conteudística nas respostas dos professores.

${ }^{4}$ A noção de Etnomatemática foi construída por D’Ambrósio (2002), na década de 1970, mediante o conceito (e deslocando-o) de Etnociência. Hoje é estudada em países como Estados Unidos, África do Sul e Inglaterra.

${ }^{5}$ Quando nos referirmos ao conhecimento matemático em sua apresentação disciplinar ocidental, optamos pela "Matemática" escrita em caixa alta.

${ }^{6}$ Nas quatro entrevistas e em 62 questionários.

${ }^{7}$ O lugar social nem sempre é o correspondente à posição ocupada no discurso (ORLANDI, 2009). 


\section{REFERÊNCIAS BIBLIOGRÁFICAS}

ANDRADE, E. R. Entre o desejo e a necessidade de aprender línguas: a construção de representações de língua e de aprendizagem do aluno-professor de língua inglesa. Orientador: Maria José Rodrigues Faria Coracini. 2008. 266f. Tese (Doutorado em Linguística Aplicada) - Instituto de Estudos de Linguagem, Universidade Estadual de Campinas, Campinas, 2008.

BLOOR, D. Uma abordagem naturalista da Matemática. In: TEM, Grupo (Org.). Sociologia da Matemática. Lisboa: APM, 1998a. (Cadernos de Educação e Matemática, 3).

. Poderá existir uma matemática alternativa? In: TEM, Grupo (Org.). Sociologia da Matemática. Lisboa: APM, 1998b (Cadernos de Educação e Matemática, 3).

D'AMBrosio, U. Etnomatemática: elo entre as tradições e a modernidade. Belo Horizonte: Autêntica, 2002.

DUVEEN, G. Introdução: o poder das idéias. In: MOSCOVICI, S. Representações Sociais: investigações em psicologia social. Petrópolis: Vozes, 2004. p. 7-28.

GOMES, M. L. M. Quatro visões iluministas sobre a educação matemática: Diderot, D’Alambert, Condillac e Condorcet. Orientador: Antonio Miguel. 2003. 291p. Tese (Doutorado em Educação) - Faculdade de Educação, Universidade Estadual de Campinas, Campinas, 2003.

GUILHAUMOU, J; MALDIDIER, D. Efeitos do arquivo. A análise do discurso no lado da história. In: ORLANDI, E. P. (Org.). Gestos de leitura: da história no discurso. 2 ed. Campinas: Editora da Unicamp, 1997. p. 163-178.

HARVEY, D. Condição pós-moderna: uma pesquisa sobre as origens da mudança cultural. 16 ed. São Paulo: Edições Loyola, 2007.

JODELET, D. (org.). As Representações Sociais. Rio de Janeiro: EdUERJ, 2001. . Loucuras e representações sociais. Petrópolis: Vozes, 2005.

JOVCHELOVITCH, Sandra. Representações sociais e esfera pública: a construção simbólica dos espaços públicos no Brasil. Petrópolis: Vozes, 2000.

MACHADO, N. J. Matemática e língua materna: análise de uma impregnação mútua. 3 ed. São Paulo: Cortez, 1993.

MARIANI, B. Textos e conceitos fundadores de Michel Pêcheux: uma retomada em Althusser e Lacan. Alfa, São Paulo, v. 54, n. 1, p. 113-127, 2010.

MOSCOVICI, S. Representações Sociais: investigações em psicologia social. Petrópolis: Vozes, 2004.

ORLANDI, E. P. Discurso e Leitura. São Paulo: Cortez, 1988. . A linguagem e seu funcionamento. 4 ed. Campinas: Pontes, 1996.

. Discurso e texto: formulação e circulação dos sentidos. 2 ed. Campinas: Pontes, 2005.

. Lingua e conbecimento lingüístico: para uma história das idéias no Brasil. São Paulo:

Cortez, 2002.

Análise de discurso: princípios e procedimentos. 8. ed. Campinas: Pontes, 2009.

PÊCHEUX, M. Semântica e discurso: uma crítica à afirmação do óbvio. 2 ed. São Paulo: Editora da UNICAMP, 1995.

. O discurso: estrutura ou acontecimento. 2 ed. Campinas: Pontes, 1997.

PERRY, A. As origens da pós-modernidade. Rio de Janeiro: Jorge Zahar, 1999.

SANTALÓ, L. A. La matemática: una filosofia y una técnica. Barcelona: Ariel, 1994.

. Aportes para seguir enseñando matemática. In: SANTALÓ, Luis Antonio (Org.). Enfoques:

hacia una didáctica humanista de la matemática. Buenos Aires: Troqvel Educación, 1999.

SOUZA FILHO, E. A. A análise das representações sociais. In: SPINK, Mary Jane (org.). O conbecimento no cotidiano: as representações sociais na perspectiva da psicologia social. São Paulo: Brasiliense, 1995.

STRUIK, D. Sobre a Sociologia da Matemática. In: TEM, Grupo (Org.). Sociologia da Matemática.

Lisboa: APM, 1998 (Cadernos de Educação e Matemática, 3).

VESCHI, J. L. Nas espumas do tempo. Rio de Janeiro: Butiá, 1996 
WILDER, R. A base cultural da Matemática. In: TEM, Grupo (Org.). Sociologia da Matemática.

Lisboa: APM, 1998 (Cadernos de Educação e Matemática, 3).

Data Recebimento: 29/01/2014

Data Aprovação: 24/01/2014

Data Versão final: 13/05/2014

\section{Contato:}

Universidade Estadual de Maringá (UEM)

Departamento de Fundamentos da Educação (DFE)

Avenida Colombo, 5790 - Jardim Universitário - bloco I-12 - secretaria do DFE Maringá, PR - Brasil

CEP: $87020-900$ 